NBER WORKING PAPER SERIES

\title{
WHAT CALLS TO ARMS? INTERNATIONAL EVIDENCE ON INTEREST RATES AND THE CHOICE OF ADJUSTABLE-RATE MORTGAGES
}

\author{
Cristian Badarinza \\ John Y. Campbell \\ Tarun Ramadorai \\ Working Paper 20408 \\ http://www.nber.org/papers/w20408 \\ NATIONAL BUREAU OF ECONOMIC RESEARCH \\ 1050 Massachusetts Avenue \\ Cambridge, MA 02138 \\ August 2014
}

We gratefully acknowledge the Sloan Foundation for financial support. We thank Gene Amromin, Simon Gilchrist, Urban Jermann, Ralph Koijen, Stijn van Nieuwerburgh, and participants at the European Conference on Household Finance for many useful comments, and Joshua Abel and Gaurav Kankanhalli for excellent research assistance. The views expressed herein are those of the authors and do not necessarily reflect the views of the National Bureau of Economic Research.

NBER working papers are circulated for discussion and comment purposes. They have not been peerreviewed or been subject to the review by the NBER Board of Directors that accompanies official NBER publications.

(C) 2014 by Cristian Badarinza, John Y. Campbell, and Tarun Ramadorai. All rights reserved. Short sections of text, not to exceed two paragraphs, may be quoted without explicit permission provided that full credit, including (C) notice, is given to the source. 
What Calls to ARMs? International Evidence on Interest Rates and the Choice of Adjustable-Rate Mortgages

Cristian Badarinza, John Y. Campbell, and Tarun Ramadorai

NBER Working Paper No. 20408

August 2014, Revised September 2015

JEL No. D14,E43,G21

\section{ABSTRACT}

The relative popularity of adjustable-rate mortgages (ARMs) and fixed-rate mort- gages (FRMs) varies considerably both across countries and over time. We ask how movements in current and expected future interest rates affect the share of ARMs in total mortgage issuance. Using a nine-country panel and instrumental variables methods, we present evidence that near-term (one-year) rational expectations of future movements in ARM rates do affect mortgage choice, particularly in more recent data since 2001. However longer-term (three-year) rational forecasts of ARM rates have a relatively weak effect, and the current spread between FRM and ARM rates also matters, suggesting that households are concerned with current interest costs as well as with lifetime cost minimization. These conclusions are robust to alternative (adaptive and survey-based) models of household expectations.

Cristian Badarinza

Said Business School

University of Oxford

Park End Street

Oxford, OX1 1HP

UK

cristian.badarinza@sbs.ox.ac.uk

John Y. Campbell

Morton L. and Carole S.

Olshan Professor of Economics

Department of Economics

Harvard University

Littauer Center 213

Cambridge, MA 02138

and NBER

john_campbell@harvard.edu
Tarun Ramadorai

University of Oxford

Said Business School

Park End St.

Oxford OX1 1HP

United Kingdom

tarun.ramadorai@sbs.ox.ac.uk

A data appendix is available at:

http://www.nber.org/data-appendix/w20408 


\section{Introduction}

The structure of housing finance is highly variable both across countries and over time. One of the most important aspects of this structure from the perspective of macroeconomics is the interest rate schedule applicable over the life of a mortgage loan. Mortgage rate provisions can broadly be categorized into two groups. Fixed-rate mortgages (FRMs) entail a constant nominal interest rate throughout the life of the mortgage. Adjustable-rate mortgages (ARMs) have an interest rate that varies over the life of the contract in relation to market conditions. The share of mortgages issued that are ARMs (the "ARM share") exhibits significant cross-country and time-series variation. In the US, for example, the dominant mortgage is normally a 30-year FRM, but ARMs were unusually popular in the late 1980s, mid 1990s, and mid 2000s; whereas in the UK, it is difficult to find an interest rate fixation period that is much above 5 years.

These differences in the structure of housing finance influence the monetary policy transmission mechanism (Bernanke and Gertler 1995), as movements in short-term market interest rates directly affect the budgets of all ARM borrowers, while FRM borrowers are only affected by long-term interest rates, and then only if rates fall and these borrowers are able to refinance their mortgages (Taylor 1995, Miles 2004, Villar Burke 2015). In the period of declining interest rates since the Great Recession, there is some evidence that monetary policy has had a stronger stimulative effect in areas of the US where ARMs are more commonly used (Di Maggio, Kermani, and Ramcharan 2015, Keys, Piskorski, Seru, and Yao 2014). While this might lead central banks to prefer a high ARM share, as suggested in a widely publicized speech by Alan Greenspan (2004), the ARM share is an outcome of household choice albeit influenced by housing finance regulation.

Our goal in this paper is to understand the determinants of the cross- and within-country variation in the ARM share, with an emphasis on households' reactions to movements in interest rates. Our analysis also sheds light on the extent to which households are forward-looking when choosing the form of their mortgages. This question of households' forward-looking behavior has been studied extensively in macroeconomics, often in relation to consumptionsmoothing (e.g. Souleles 1999, Agarwal, Liu, and Souleles 2007, and Parker 2014). 
Reasoning based on simple rational optimization offers guidance about the likely determinants of household mortgage choice between ARMs and FRMs. Absent borrowing constraints, the rational decision between fixed- and variable-rate mortgages depends on the expected future costs borne by the borrower over the life of the loan, in relation to the risks that these costs will be higher or lower than expected. If the relative risks of ARMs and FRMs are relatively stable, the primary determinant of variation in the ARM share over time should be the spread between the current fixed rate and the expectation of the average adjustable rate over the life of the mortgage.

Empirical research (Koijen, Van Hemert, and Van Nieuwerburgh, KHN 2009, and Botsch and Malmendier 2015) has provided evidence which is broadly consistent with this reasoning, in the sense that households appear to estimate costs over the duration of the loan when choosing mortgages. However this research adds a behavioral twist to the theory, deviating from the premise that households form their expectations of mortgage costs rationally. For example, KHN (2009) posit that households estimate the future path of adjustable rates using a simple rule of thumb which is well approximated by a backward moving average of realized ARM rates. They find evidence using US data that appears consistent with this hypothesis. A different deviation from rational expectation formation is posited by Botsch and Malmendier (2015), who suggest that households who place greater subjective probability on the possibility of high future inflation are more likely to choose fixed rate mortgages. They measure these subjective probabilities using the inflation experienced by households over their lifetimes, under the assumption that high experienced inflation causes increases in households' subjective probability of high future inflation.

An alternative theoretical perspective is offered by Campbell and Cocco (2003, 2015), who explore household mortgage choice in the presence of borrowing constraints. Such constraints will cause households to care primarily about current interest costs, rather than costs over the life of the loan. This line of reasoning implies that the spread between the FRM rate and the current ARM rate should be the primary determinant of mortgage choice. Households may also focus on the current rate spread if they are constrained in the size of house they can buy by bank limitations on the maximum interest-payment-to-income ratio 
at the origination of the mortgage. ${ }^{1}$

It is plausible that both current cost minimization and forward-looking behavior (whether behavioral or rational) are important determinants of mortgage choice. However, it is difficult to ascertain their relative weights in household mortgage choice using time-series data from a single country, because interest rates are persistent and the available time-series on the ARM share is relatively short. This problem may be exacerbated by inertia among market participants. For example, it may take time for banks to shift their marketing strategies gradually towards mortgage forms that they think will have greater customer appeal in current market conditions. In turn, households may be slow to respond to movements in rates if they tend to copy other households who have taken out mortgages recently, or simply if their expectations adjust gradually over time.

To surmount these obstacles, and to arrive at a more precise understanding of the determinants of household mortgage choice, we compile panel data on the ARM share, average interest rate fixation periods, ARM and FRM rates, interbank rates, government bond yields, and survey forecasts of interest rates from nine countries. This helps to alleviate the constraints imposed by a single country study, and allows us to bring more statistical power to bear on the problem. While there are numerous comparative studies of mortgage market structure across countries (for example, Lea 2011, Lea and Sanders 2011, IMF 2011, Bardhan, Edelstein, and Kroll 2012), we are unaware of any study that uses cross-country data to study time-variation in average fixation periods or the ARM share.

Using our nine-country panel, we estimate a series of reduced-form econometric models that evaluate the relative weights of current cost minimization and longer-term cost minimization as determinants of mortgage product choice. Each model allows both the spread of the FRM over the current ARM rate, and the spread of the FRM rate over average expected future ARM rates to influence the current ARM share and fixation period. The models differ in the way they model household expectations of future ARM rates.

\footnotetext{
${ }^{1}$ Consistent with this, empirical papers by Brueckner and Follain (1988), Coulibaly and Li (2009), and Dhillon, Shilling, and Sirmans (1987) use household-level data on mortgage choice and include the current interest spread as an explanatory variable. Johnson and Li (2011) use data from the US Consumer Expenditure Survey to argue that adjustable-rate mortgage borrowers appear particularly likely to be borrowingconstrained.
} 
Our first approach assumes that households have rational expectations. Using a panel instrumental variables (IV) method, we instrument realized future ARM rates (over horizons between one and three years, assuming stationary as well as I(1) interest rate processes) with current and past mortgage rates and government bond yields. This setup allows us to test both the hypothesis that expected future changes in ARM rates have no influence on current mortgage choice (as implied by current cost minimization) and the hypothesis that the current spread correlates with the ARM share only to the extent that it predicts future ARM rates (as implied by longer-term cost minimization).

In our full sample, while our results suggest that current cost minimization is the proximate driver of household mortgage choice, we also find that households anticipate movements in ARM rates within the first year after mortgage origination. Within the last decade, there is more evidence for the relevance of longer-term cost minimization. These results are robust to the inclusion of time fixed effects.

Our second approach assumes that households have adaptive expectations, forecasting average future ARM rates with a backwards moving average of ARM rates. We do confirm in the US data studied by KHN 2009 that a backwards moving average of ARM rates helps to determine the ARM share. However we find little evidence of this mechanism for the other countries in the panel.

Our third approach uses one-year-ahead professional survey forecasts of short-term nominal interest rates. Short-term interest rates influence ARM rates both directly (for tracker or index-linked mortgages) and indirectly (through the cost structure of banks), so their future path is a substantial determinant of the expected relative costs of FRM and ARM contracts over the life of the mortgage. After verifying that the survey forecasts are near-rational predictors of short-term interest rate movements, we use the forecasts both as additional instruments in our basic rational expectations model, and as additional explanatory variables that may directly affect household mortgage choice.

In a model where households are assumed to look forward one year, survey forecasts correlate with the ARM share only because they predict movements in future ARM rates over the next year. In a longer-term (three-year) forecasting model, however, the survey 
forecasts have direct explanatory power for the ARM share, implying that households react more strongly to survey forecasts than to other variables that predict future ARM rates. This may be because households neglect the ability of our other instruments to predict future ARM rates, or because they react to noise in the survey forecasts that is not relevant for predicting ARM rates over a three-year horizon.

Our panel analysis is focused on uncovering the determinants of relatively short-term variation in the ARM share. Of course, there are likely broader macroeconomic determinants of preferred mortgage form across countries, which help to determine the country-average ARM share. One potentially important determinant is inflation volatility. If a fixed-rate mortgage cannot be prepaid without penalties, as in Germany or in the US in an environment of falling house prices, then a FRM is risky to the extent that inflation is volatile and persistent. If it can be prepaid without penalties, as in the US in an environment of rising house prices, then inflation volatility increases the FRM rate that banks will want to charge. While inflation volatility also makes an ARM risky for a borrowing-constrained household, because it makes the timing of required payments more volatile in real terms, it is likely that the net effect is to shift demand away from FRMs and toward ARMs (Campbell and Cocco 2003, Campbell 2013). While this is not our primary focus, we do find suggestive evidence for the role of historical country-specific inflation volatility in explaining the country-average ARM share using 14 countries including the nine countries in our panel analysis.

The organization of the paper is as follows. Section 2 describes the cross-country data that we compile and employ in our study. Section 3 describes the econometric methodology that we use to evaluate the roles of current cost minimization and longer-term cost minimization in household mortgage choice. Section 4 estimates these models. Section 5 explores robustness and presents cross-country evidence on the role of historical inflation volatility in explaining the cross-country average ARM share. Section 6 concludes. An online appendix, Badarinza, Campbell, and Ramadorai (2014), provides additional details about our data sources and econometric procedures, and additional empirical results. 


\section{Data}

Our panel analysis covers nine countries: Australia, Belgium, Denmark, Greece, Ireland, Italy, Netherlands, Sweden, and the United States. For these countries, we compile data on mortgage issuance volumes of both FRMs and ARMs, and mortgage interest rates, which we measure as the average effective annual interest rates on new residential mortgage loans, distinguishing between ARM and FRM contracts. In order to insure comparability across countries, we classify any mortgage loan which either pays a variable interest rate until it matures, or has an initial fixation period of up to and including one year as an ARM. This includes "tracker" contracts with interest rates which are linked to underlying indices or benchmark interest rates.

More specifically, for countries which are part of the Eurozone, we obtain aggregate monthly data on mortgage volumes and interest rates on new mortgage loans from the statistical repositories of respective national central banks. These data are part of the harmonized system, introduced by the European Central Bank in 2003, which reports and aggregates credit volumes from country-level mortgage finance institutions.

For Sweden, we use the Swedish statistical agency's Financial Market Statistics report, which contains monthly series of volumes and interest rates on new housing credit agreements, and goes back to 1996. For Australia, we use data released by the Australian Bureau of Statistics, which covers the period from 1991 to the present. For Denmark, we use the historical time series of financial statistics reported by the Danmarks Nationalbank, which begins in 2003 .

Our mortgage data for the US are taken from the Monthly Interest Rate Survey, collected since 1992 by the Federal Housing Finance Agency. Towards the end of the sample, the share of adjustable-rate mortgages becomes very low in the US market and we therefore impute values for the corresponding interest rates, in order to insure representativeness and time series comparability. We verify that our results are not driven by this imputation of rates, and give further details of this procedure in the online appendix.

As a robustness check in the paper, we employ average interest-rate fixation periods rather than a simple binary classification of mortgages as FRMs or ARMs. For this analysis, for 
the US, we calculate monthly population-weighted averages of interest rate fixation periods at the individual loan level, using data from the Monthly Interest Rate Survey. For all other countries, we approximate the time series of interest rate fixation periods by using the market share of mortgages for three different fixation period categories: 1 to 5 years, 5 to 10 years and above 10 years. We calculate the average fixation periods as weighted averages of interval means, i.e., 1-year for ARMs, and 3, 7 and 20 years for FRMs, respectively. ${ }^{2}$

Another source of data that we employ in the paper is variables which proxy for variation in broader funding costs. We employ the 3-month interbank lending rate and the 5-year sovereign bond yield in all countries, as well as the inflation rate, which we measure as the monthly year-on-year change of the consumer price index (CPI). The data source for both interest rates and CPI statistics is Datastream.

We obtain data on professional interest rate forecasts from Consensus Economics, as reported in their "Consensus Forecasts Report". The Report is based on surveys of local economists, primarily employed by large financial institutions. These economists predict the evolution of nominal 3-month interest rates over the 12-month period following the survey date. We compute country-level monthly time series by cross-sectionally averaging forecasts across the set of respondents in each country. The disaggregated data are not available for Denmark, Belgium, Ireland and Greece. We therefore drop Denmark from any analysis which uses survey forecast data. For Belgium, Ireland, and Greece, we use data on survey forecasts for the Eurozone.

Towards the end of the paper, we conduct a pure cross-sectional analysis of the determinants of the ARM share, and include additional countries in this analysis. For these countries which are not part of our panel analysis (but are included in our pure cross-country analysis), we source ARM share and inflation data from national central banks and Datastream. Additional details about all data employed in the paper are provided in the online appendix. We also present broader institutional information about these mortgage markets in a separate institutional appendix, Badarinza et al. (2014), also available online.

\footnotetext{
${ }^{2}$ The data for Australia, Ireland and Sweden do not allow for the computation of these series.
} 


\subsection{Cross-sectional and time-series variation in the ARM share}

Table 1 reports summary statistics on the ARM share - the percentage share of adjustablerate mortgages in the total volume of new mortgage loans issued to households - and, for countries where the data are available, the average period of initial interest rate fixation in years. We divide our countries into two groups, using the following algorithm. If the volatility (time-series standard deviation) of the ARM share exceeds five percentage points, and if the volatility of the average initial interest rate fixation period is either unmeasured or at least equal to 1 year, then we classify the country as one with significant time-series variation in mortgage choice.

The top panel of the table shows the nine countries that satisfy both of these conditions, and which we include in our panel estimation: Australia, Belgium, Denmark, Greece, Ireland, Italy, the Netherlands, Sweden, and the USA. The bottom panel of the table shows countries that do not satisfy these conditions, in other words countries where there is a dominant mortgage form with minimal time-variation: Finland, Germany, Portugal, Spain, and the UK. Most of these countries have mortgage systems dominated by ARMs, but the mortgage system in Germany is dominated by FRMs. The UK and Spain are two countries where the ARM share does vary through time, but in a fashion that is not economically meaningful because mortgage loans in these countries have very low average fixation periods (far less than three years, on average) which hardly vary over time. In other words, "fixed-rate" mortgages in these countries have such short fixation periods that they are barely distinguishable from "adjustable-rate" mortgages.

Table 1 documents considerable time-series variation in the ARM share within the countries selected by our algorithm. The time-series standard deviation of the ARM share ranges from roughly $80 \%$ of the mean ARM share in the US to roughly $6 \%$ of the mean in Australia. Figure 1 plots the history of the ARM share in each of these nine countries, along with the contemporaneous spread between FRM and ARM rates. The figure shows both temporary fluctuations in the ARM share that are typically correlated with the FRM-ARM spread, and some longer-term movements that vary across countries. ${ }^{3}$ For example Sweden moves

\footnotetext{
${ }^{3} \mathrm{An}$ increase in long-term borrowing costs after the crisis is especially pronounced in Ireland. Irish banks experienced higher funding costs as of October 2008, which led to a significant increase in the spread between
} 
towards a greater average ARM share over the sample period, whereas the US moves towards a lower average ARM share.

\subsection{Survey forecasts of interest rates}

In Table 2, we assess the information contained in Consensus Economics survey forecasts for future realizations of interest rates using the following regression specification, which we estimate both country-by-country and in a panel with fixed effects:

$$
R_{i, t+12}^{f}-R_{i, t}^{f}=\alpha_{i}+\beta_{i}\left(R_{i, t, t+12}^{f, S}-R_{i, t}^{f}\right)+\varepsilon_{i, t+12}
$$

Here, $R_{i, t}^{f}$ is the 3 -month interest rate in country $i$ in period $t$ and $R_{i, t, t+12}^{f, S}$ is the 12 -month ahead average consensus survey forecast in country $i$ in period $t$. The hypothesis that the survey forecasts are primarily rational expectations of future interest rates in country $i$ implies that we should estimate an intercept $\alpha_{i}=0$ and a slope coefficient $\beta_{i}=1$. More generally, if the survey forecasts contain relevant information about future interest rate changes but are quite far from rational, then we should find $\beta_{i}>0$ even if $\alpha_{i} \neq 0$ and $\beta_{i} \neq 1$.

Table 2 estimates equation (1) for each country separately, and then for the panel as a whole. The first column of Panel A of the table reports uniformly negative intercepts that are statistically significant in Sweden, the Netherlands and the Eurozone. In other words, survey respondents tend to predict slightly higher changes in interest rates than the ones that actually materialize one year later. The second column of Panel A reports uniformly positive slope coefficients that are significantly different from zero in all countries except Australia, and insignificantly different from one in all countries except the Eurozone. ${ }^{4}$ The third column of Panel A shows that the rational expectations hypothesis that the intercept and slope coefficients equal zero and one, respectively, can be rejected at the $5 \%$ level or better for all countries except the US and Italy. ${ }^{5}$

FRMs and ARMs. A comprehensive discussion of developments in the Irish mortgage market around the crisis period is given by Goggin et al. (2012).

${ }^{4}$ The data sample for short-term interest rate forecasts at the level of the Eurozone only covers the period after 2005, as indicated in Table 1. In this case, the rapid decline of interest rates during the financial crisis leads us to observe a slope coefficient higher than one.

${ }^{5}$ For robustness, we also check the relationship between Consensus professional forecaster data and house- 
Panel B of Table 2 imposes a common slope across countries but allows country-specific fixed effects, and shows that the estimated slope is 1.02, insignificantly different from one. For the purposes of our analysis, the slight upwards bias in the forecasts observed in Panel A appears not to be particularly important, only affecting the estimated regression constants and country fixed effects. We conclude that the one-year ahead survey forecasts contain relevant information about future interest rates, and are close to rational forecasts of oneyear changes in these short rates.

\section{Methodology}

In this section we present the methodology that we use to discover whether the positive correlation between the ARM share and the spread between FRM and ARM rates, illustrated in Figure 1, is driven by short-term cost minimization, or by rational forecasts of future ARM rates.

We propose a simple model to distinguish between alternative explanations for variation in the ARM share across countries $i$ and months $t$ :

$$
\begin{aligned}
A R M S H A R E_{i, t}=\mu_{i} & +\rho A R M S H A R E_{i, t-1}+\beta_{C}\left(F R M_{i, t}-A R M_{i, t}\right) \\
& +\beta_{L}\left(F R M_{i, t}-\hat{\mathrm{E}}_{i, t}\left[\overline{A R M}_{i, t, t+T}\right]\right)+\nu_{i, t} .
\end{aligned}
$$

In this equation, $A R M S H A R E_{i, t}$ is the percent share of ARMs in total mortgage issuance in each month, and $A R M_{i, t}$ and $F R M_{i, t}$ are country-specific monthly mortgage interest rates on ARMs and FRMs respectively. $\overline{A R M}_{i, t, t+T}$ is the forward-looking simple moving average of the ARM rate in country $i$, evaluated between time $t$ and time $t+T$, where $T$ is measured in calendar years. ${ }^{6}$

In our panel estimation, we allow for country-specific intercept terms $\mu_{i}$, which control

hold interest rate survey expectations (the Michigan survey data) for the US. We discuss these results more fully below and in the online appendix.

${ }^{6}$ The horizon $T$ at which future payment streams are evaluated should, in theory, correspond to the average fixation period for fixed-rate mortgages in each country. However, as Table 1 shows, we have relatively short sample periods so we do not extend $T$ beyond 3 years as doing so would leave us with a remaining sample which is too short for accurate estimation. 
for the possibility that there may be pure time-invariant cross-country variation in the ARM share. We also include the lagged dependent variable $A R M S H A R E_{i, t-1}$, in order to capture the effect of inertia on the part of households or mortgage providers. As mentioned earlier, it may take time for banks to shift their marketing strategies gradually towards mortgage forms that they think will work better, or for households to respond to movements in interest rates.

Interest rates are allowed to affect mortgage choice in two ways. Current cost minimization implies a positive contemporaneous relationship between the mortgage rate spread and the share of ARMs, and this channel is captured by the coefficient $\beta_{C}$. On the other hand, if households rationally forecast variation in ARM rates over the longer-term to evaluate the trade-off between ARMs and FRMs, the relevant variable is the spread between current FRM rates and expectations about average ARM rates over the horizon $T$. We therefore interpret a positive and statistically significant coefficient $\beta_{L}$ as evidence for rational long-term cost minimization by households.

This setup requires us to estimate household expectations of future average ARM rates,

$\hat{\mathrm{E}}_{i, t}\left[\overline{A R M}_{i, t, t+T}\right]$. We consider three alternative models for household expectations-rational expectations, adaptive expectations, and survey proxies for expectations - each of which leads to its own empirical specification.

\subsection{Rational household expectations}

If household expectations are rational, we can use a panel instrumental variables approach, replacing expected future ARM rates in equation (2) with realized future ARM rates, and then instrumenting these future rates with current and lagged interest rates. This approach can be described as a two-stage procedure.

The first-stage regression uses current and past mortgage rates, as well as nominal shortterm interest rates and government bond yields, to predict $\overline{A R M}_{i, t, t+T}$ :

$$
\overline{A R M}_{i, t, t+T}=\alpha_{i}+\gamma_{1} A R M_{i, t}+\gamma_{2} F R M_{i, t}+\gamma_{3} \overline{A R M}_{i, t-K, t}+\gamma_{4} B_{i, t}^{5}+\gamma_{5} R_{i, t}^{f}+\varepsilon_{i, t} .
$$


Employing the same notation as earlier, $\overline{A R M}_{i, t, t-K}$ is the backward-looking moving average of the ARM rate in country $i$, evaluated between time $t$ and time $t-K$, where $K$ is once again measured in calendar years. We also include the 3 -month interest rate $R_{i, t}^{f}$ and the 5-year government bond yield $B_{i, t}^{5}$ as explanatory variables. Their separate inclusion allows for benchmark rates and the excess of the $A R M$ or $F R M$ rates over these benchmark rates to forecast future ARM rates with different coefficients.

A variant of this approach modifies equation (3) to account for potential non-stationarity in interest rates. We assume that in the case of such non-stationarity, all interest rates are cointegrated, with a coefficient of cointegration equal to 1 for any given pair of interest rates. Campbell and Shiller (1987) show that such cointegration arises if there is a unit root in the short-term interest rate and the expectations hypothesis holds; the same will be true in the presence of time-varying risk premia, provided that risk premia follow a stationary process. Under this set of assumptions, in order to forecast $\overline{A R M}_{i, t, t+T}$ we estimate the following equation in which both right- and left-hand-side variables are stationary:

$$
\begin{aligned}
\overline{A R M}_{i, t, t+T}-A R M_{i, t}= & \varphi_{i}+\phi_{1}\left(F R M_{i, t}-A R M_{i, t}\right)+\phi_{2}\left(\overline{A R M}_{i, t-K, t}-A R M_{i, t}\right) \\
& +\phi_{3}\left(B_{i, t}^{5}-R_{i, t}^{f}\right)+\xi_{i, t} .
\end{aligned}
$$

In the second stage, $\hat{\mathrm{E}}_{i, t}\left[\overline{A R M}_{i, t, t+T}\right]$ is the fitted value from estimation of (3) or (4), which is then substituted back into equation (2).

Our identification strategy is straightforward. If the current spread between FRM and ARM rates $\left(F R M_{i, t}-A R M_{i, t}\right)$ predicts $A R M S H A R E_{i, t}$ only to the extent that the spread forecasts $\overline{A R M}_{i, t, t+T}$, this will "knock out" any role for $\beta_{C}$ in equation (2) given our instrumental variables approach. However if current cost minimization drives the ARM share, then $\beta_{C}$ will continue to be important. The relative significance of the two coefficients $\beta_{C}$ and $\beta_{L}$ in equation (2) allows us to measure the relative importance of current and longer-term cost minimization in household mortgage choice.

A few notes on our estimation procedure and results: First, we set $T=3$ years and $K=1$ year in the benchmark case in our estimation. We also consider values of $T=1,2$ and $K=2,3$ years, and show results in the paper for $T=1$, in the interest of preserving 
clarity of exposition. The results for $K=2,3$ and $T=2$ years are available in the online appendix.

Second, estimation of equation (3) requires measuring a backward moving average of ARM rates. Since our sample periods are quite short for many countries, we wish to avoid shortening them further for models with a high $K$. For this reason, when $K>1$, we impute ("back-cast") ARM rates prior to the beginning of our sample using nominal shortterm interest rates, which are available earlier than ARM rates, and provide details of this procedure in the online appendix. This allows us to present all results for a common sample period. Our results are very similar if we shorten the sample as $K$ increases rather than using this imputation approach.

Third, we calculate standard errors for all coefficients using a non-parametric bootstrap procedure, along the lines of Politis and Romano (1994), and as employed by Ramadorai (2012). These errors are robust to contemporaneous cross-country correlation of the error terms, in addition to being robust to heteroskedasticity. Details are provided in the online appendix.

\subsection{Adaptive household expectations}

An alternative approach follows KHN (2009) in assuming that household expectations follow a simple adaptive process, $\hat{\mathrm{E}}_{i, t}\left[\overline{A R M}_{i, t, t+T}\right]=\overline{A R M}_{i, t-K, t}$, which we simply substitute back into equation (2). In this case we use OLS to estimate the following specification:

$$
\begin{aligned}
\operatorname{ARMSHARE}_{i, t}=\mu_{i} & +\rho A R M S H A R E_{i, t-1}+\beta_{C}\left(F R M_{i, t}-A R M_{i, t}\right) \\
& +\beta_{L}\left(F R M_{i, t}-\overline{A R M}_{i, t-K, t}\right)+\nu_{i, t} .
\end{aligned}
$$

Current cost minimization implies that $\beta_{C}>0$ and $\beta_{L}=0$, while KHN's adaptive forwardlooking cost minimization implies that $\beta_{C}=0$ and $\beta_{L}>0$. 


\subsection{Survey proxies for household expectations}

Finally, we consider survey-based data on professional interest rate forecasts. These direct measures of agents' expectations are well suited to serve as instruments for expected future $\mathrm{ARM}$ rates, as they are forward-looking in nature, and potentially reflect more relevant information than current realizations of term structure variables. We also allow for the possibility that the survey-based interest rate forecasts influence mortgage choice directlya possibility if household expectations are not fully rational, but are correlated with survey forecasts.

We alter our first-stage regressions to include survey forecasts $R_{i, t, t+12}^{f, S}$ :

$$
\begin{aligned}
\overline{A R M}_{i, t, t+T}= & \alpha_{i}+\gamma_{1} A R M_{i, t}+\gamma_{2} F R M_{i, t}+\gamma_{3}{\overline{A R M_{i, t-K, t}}}+\gamma_{4} B_{i, t}^{5} \\
& +\gamma_{5} R_{i, t}^{f}+\gamma_{6} R_{i, t, t+12}^{f, S}+\varepsilon_{i, t}
\end{aligned}
$$

and:

$$
\begin{aligned}
\overline{A R M}_{i, t, t+T}-A R M_{i, t}= & \varphi_{i}+\phi_{1}\left(F R M_{i, t}-A R M_{i, t}\right)+\phi_{2}\left(\overline{A R M}_{i, t-K, t}-A R M_{i, t}\right) \\
& +\phi_{3}\left(B_{i, t}^{5}-R_{i, t}^{f}\right)+\phi_{4}\left(R_{i, t, t+12}^{f, S}-R_{i, t}^{f}\right)+\xi_{i, t} .
\end{aligned}
$$

Similarly, we alter our main regression to include the survey forecast of the future change in the short-term interest rate:

$$
\begin{aligned}
\operatorname{ARMSHARE}_{i, t}= & \mu_{i}+\rho A R M S H A R E_{i, t-1}+\beta_{C}\left(F R M_{i, t}-A R M_{i, t}\right) \\
& +\beta_{L}\left(F R M_{i, t}-\overline{A R M}_{i, t, t+T}\right)+\beta_{S}\left(R_{i, t}^{f}-R_{i, t, t+12}^{f, S}\right)+\nu_{i, t},
\end{aligned}
$$

To the extent that households have rational expectations of future interest rates, the survey forecasts should only be useful instruments in the first-stage regressions and should have no additional explanatory power for the ARM share when included directly in equation (8). That is, we should find $\beta_{S}=0$. We test this exclusion restriction in both the stationary and the unit-root panel models. Alternatively, a positive and statistically significant coefficient $\beta_{S}$ implies that a survey forecast of increasing short-term interest rates over the course of the 
next year leads to a decrease in the ARM share, beyond any information that the one-year forecasts may contain about the levels of future ARM rates.

\section{Estimation of mortgage choice models}

\subsection{Rational expectations}

Table 3 asks whether the ARM share is driven by the current FRM-ARM spread or by the spread of the FRM rate over rational expectations of an average of future ARM rates. We estimate equation (2) by instrumental variables, where equation (3) is our first-stage regression, assuming that interest rates are stationary. ${ }^{7}$

The table is divided into two sets of rows, each corresponding to a different sample: the full sample, and a more recent sample beginning in 2001. We also differentiate across two sets of columns, between panel regressions that do and do not include the US. The exclusion of the US is intended to provide an "out-of-sample" evaluation of the modelseveral studies including Brueckner and Follain (1988), KHN (2009), and Moench et al. (2010) have attempted to explain the ARM share in the US, but to our knowledge, ours is the first academic study attempting to explain such variation in the additional 8 countries in our panel.

In our benchmark presentation of the results, we set $T=3$ years, and show estimated coefficients $\beta_{C}$ and $\beta_{L}$. As described earlier, $\beta_{C}$ measures the impact of the current spread between FRM and ARM rates on the ARM share, while $\beta_{L}$ measures the role of longer-term forecasts, i.e., the impact of the spread between the current FRM rate and the average of expected future ARM rates, on the ARM share.

Across all specifications, we obtain a large coefficient $\beta_{C}$ that is always significant at the $1 \%$ level. Moreover, we find almost no evidence for longer-term forward-looking behavior in the full sample: the coefficient $\beta_{L}$ is small and statistically insignificant. If we shorten the sample to start in 2001, we do estimate $\beta_{L}$ to be statistically significant, but its magnitude

\footnotetext{
${ }^{7}$ In the online appendix, we also report panel estimation results assuming that interest rates have a common unique unit root. In this case, we estimate equation (2) by instrumental variables, where equation (4) is our first-stage regression.
} 
is still roughly half the magnitude of $\beta_{C}$. In the online appendix, we show that our results are unaffected by the choice of $K$, the backward window for averaging ARM rates.

We consider the alternative case $T=1$ in the last two columns of Table 3 . That is, we compare a FRM-ARM spread that includes the current ARM rate with a near-term alternative that includes an average expected ARM rate over the next year. In contrast with the benchmark $T=3$ case, when $T=1$, we typically obtain a small and statistically insignificant coefficient $\beta_{C}$ and a larger coefficient $\beta_{L}$ which is significant at the $1 \%$ level. This provides evidence for near-term forward-looking behavior on the part of households, especially in recent data. This contrast suggests that households may experience greater difficulty making accurate longer-term forecasts, which are more relevant for lifetime mortgage cost comparisons.

The results assuming a unit-root interest rate process, which we report in the online appendix, are broadly consistent with those discussed above. In the benchmark case $T=3$, the coefficient $\beta_{C}$ on the current spread remains strongly statistically significant for the post-2001 sample, while the coefficient $\beta_{L}$ on the forward-looking spread is variable both in magnitude and statistical significance. The coefficients are less stable in the case $T=1$, probably reflecting the fact that fewer instruments are available in the first-stage regression for the unit-root case, so the fitted forward-looking FRM-ARM spread is more highly correlated with the current FRM-ARM spread in the second stage.

In summary, there is some evidence that household mortgage choice responds to rational forecasts of future ARM rates. This evidence is stronger for near-term forecasts of rates within the next year than for longer-term three-year forecasts, and stronger in recent data since 2001. However there is also evidence that the current FRM-ARM spread influences mortgage choice, and in most of our specifications the current spread has a greater influence than the anticipated future spread.

Table 4 estimates country-specific regressions and provides more details about the underlying coefficients from equations (2) and (3) when $K=1$ year and $T=3$ years. The first-stage regressions generate relatively consistent results across countries $-\gamma_{1}$ is positive on average, which indicates that mortgage rates are persistent over the short-run. However, 
$\gamma_{3}$ is negative, which suggests that controlling for short-run continuation, there is a tendency for ARM rates to reverse over the longer run. In the online appendix, we repeat this exercise under the assumption of a unit root in interest rates. We generally find evidence that long-short spreads, both of FRM rates over ARM rates and of longer-term government bond yields over short-term rates, tend to predict increases in ARM rates, and there is some evidence of mean-reversion in changes in ARM rates.

Our analysis also reveals that in the second stage regression, i.e., equation (2), the coefficient on the lagged ARM share is high and statistically significant. This is consistent with a high degree of inertia in mortgage markets in every country in our sample. This inertia could arise from sluggishness in the sales effort of mortgage providers, in the sense that they only gradually shift towards selling products that households are interested in buying. It could also capture households' sluggish adjustment to interest rate movements, or spillovers within the household sector-with households' mortgage decisions strongly influenced by other households' recent choices.

\subsection{Adaptive expectations}

In Table 5, we drop the assumption of rational forecasting and instead estimate rule-of-thumb models as suggested by KHN (2009).

The left-hand side of the table estimates equation (2) under the assumption of simple rule of thumb adaptive expectations. This specification results in positive coefficients $\beta_{C}$ on the spread of the FRM rate over the contemporaneous ARM rate for all countries, and for the panel as a whole. Current cost minimization seems therefore to be a consistent feature of mortgage markets around the world, robustly estimated across our set of different assumptions about the expectations formation process.

In contrast, the coefficient on the term capturing the rule-of-thumb behavior is estimated to be negative and statistically significant in most countries, suggesting that the backwardlooking nature of mortgage product choice at household level is a phenomenon restricted to US households. Moreover, the results indicate that even in the US, the importance of past ARM rates has decreased over time, with no statistically significant effects visible for the 
more recent post-2001 sub-period.

The right-hand side of the table shows what happens when we exclude the lagged dependent variable in these regressions. First, our previous findings in favour of current-cost minimization remain robust and remarkably consistent across countries. Second, we confirm the strong evidence reported by KHN (2009) in favour of backward-looking behavior in the US mortgage market: over the full sample, we find that the US ARM share rises by 9 percentage points in response to a one percentage point increase in the spread of FRM rates over a one-year moving average of ARM rates. ${ }^{8}$ However, we again find that the strength of this relationship is lower over the past decade, and reverses when we consider the cross-country panel as a whole.

\subsection{Survey expectations}

In Table 6, we add professional survey forecasts of near-term interest rate movements to our analysis. This table repeats the rational-expectations analysis of Table 3, but includes the forecasted one-year change of the nominal 3-month interest rate both as an additional explanatory variable, with coefficient $\beta_{S}$, and as an additional instrument for future average ARM rates.

Once again the results are sensitive to the forecasting horizon that we consider. In the benchmark case, the current FRM-ARM spread is always significant and the survey forecast of interest rate changes enters the regression directly in three out of four specifications, while the rationally anticipated future spread is never statistically significant. The current spread and the survey forecasts appear to drive out the rational forecast of future ARM rates in determining household mortgage choice. Thus, while households may be forward-looking in the sense that they are responsive to survey expectations of future interest-rate movements, this forward-looking behavior is not consistent with fully rational cost minimization over horizons longer than one year.

Given the evidence shown earlier in Table 2 that survey forecasts are rational predictors of short-term interest rates over the next year, conditional on the information they contain, this

\footnotetext{
${ }^{8}$ The choice of $K$ does not affect the estimated effects qualitatively. In the online appendix, we also report estimation results for the backward-looking horizon of $K=3$ years, originally considered by KHN.
} 
finding suggests that households use some but not all the information available for predicting future ARM rates over the next three years. The other instruments have independent forecasting power that is not incorporated in survey forecasts or reflected in household mortgage choice. Consistent with this, we show in the online appendix that the other instruments are jointly significant in a panel regression of one-year changes in short rates onto survey forecasts and instruments. ${ }^{9}$

The results for the case $T=1$ strengthen the evidence that over a short one-year horizon, rational interest-rate forecasts do affect mortgage choice. The current FRM-ARM spread is never significant, while the rationally anticipated future spread is significant in three out of four specifications. It is also the case in these specifications that the survey forecasts enter directly when we exclude US data.

It is worth noting an important robustness check here. We check whether the use of household expectations rather than professional survey forecasts makes a material difference to our results. Household survey expectations data are readily available for the US, where categorical data on household interest rate expectations are available from the Michigan survey. ${ }^{10}$ We check how these household expectations correlate with future interest rate realizations, recoding the categorical variables as fractions of the set of surveyed households expecting an interest rate decrease or increase. We find that household expectations in the US do appear to contain information about the future path of interest rates, confirming the results of Ang et al. (2007). We then reconstruct the instrument in equation (6), substituting these household expectations for the Consensus professional forecasts in the US. The resulting instrument has a correlation of 0.97 over the full US sample with the instrument constructed using only professional forecasts. Furthermore, the second-stage regression results for the US do not differ greatly when this substitution is made. Taken together, these results imply that in the US at least, Consensus professional forecasts are adequate proxies for household

\footnotetext{
${ }^{9} \mathrm{We}$ also note that confidence intervals are quite wide in Table 2 , so it is possible that survey forecasts contain some noise that influences mortgage choice but does not predict future movements in interest rates.

${ }^{10}$ The Eurosystem HFCS surveys which are normally used for work in household finance do not contain time series data on household interest rate expections. These data are available from other sources for Europe. Where they are available, like the Michigan household surveys in the US, they simply ask categorical questions about whether households expect interest rates to rise, fall, or remain the same in the future. We do not acquire these data for Europe, but simply check the correlation between household survey expectations and Consensus professional forecasts using the US Michigan data, recoded to permit numerical analysis.
} 
expectations. These results are available in the online appendix to the paper.

\section{$5 \quad$ Robustness and further analysis}

\subsection{Interest rate fixation periods}

In most European countries and differently from the US, fixed-rate mortgages are offered for a variety of initial fixation periods. As mentioned above, FRM contracts entail very different repayment streams in Spain and Germany, with short-term fixation (below 5 years) more common in the former and long-term fixation (above 10 years) typical for the latter.

It is also interesting to note that in the nine countries constituting our estimation sample (where the overall share of adjustable- vs. fixed-rate mortgages varies through time), we observe substantial time-variation in the market share of mortgages corresponding to different initial fixation periods. ${ }^{11}$

For example, in the Netherlands, households increasingly opted for long-term FRMs during the years preceding the financial crisis. More recently however, long-term FRMs have virtually disappeared from the Dutch market, whereas the transaction volumes of FRMs with lower fixation periods have remained broadly unchanged throughout the decade. In contrast, the increase in FRM volumes in Greece between 2006 and 2008 is associated with an increased preference for relatively shorter-duration FRMs.

As a robustness exercise, we repeat our instrumental-variables panel analysis, replacing the ARM share with the average fixation period. ${ }^{12}$ Our set of countries is substantially reduced, since disaggregated data on mortgage transaction volumes are only available for the United States, Denmark, and countries in the Eurozone (see Table 1). Nevertheless, in Table 7 we show that our results carry through in this setup. In particular, we continue to find evidence that households exhibit short-term forward looking behavior, as well as

\footnotetext{
${ }^{11}$ In the appendix, we illustrate the dynamics of the monthly transaction volumes for residential fixed-rate mortgage contracts with different initial fixation periods, grouped in three sub-categories: 1 to 5 years, 5 to 10 years and above 10 years.

${ }^{12}$ In this context, it is no longer appropriate to compute the FRM-ARM spread as a weighted average of rates across fixation periods, as this would, by construction, introduce a simultaneity bias. We therefore construct our right-hand side explanatory variables in this robustness exercise using the interest rates on contracts with fixation periods above 10 years.
} 
evidence that time-variation in the current FRM-ARM spread explains a significant portion of the dynamics of average fixation periods.

\subsection{Cross-country identification: time fixed effects}

Our panel estimation approach uses ARM share dynamics in multiple countries as a way to distinguish between alternative theories. The power of this approach depends on the extent to which mortgage interest rates and yield curve data exhibit cross-sectional heterogeneity.

Figure 1 shows that the financial crisis affected the terms of mortgage loans in a broadly similar fashion across countries: the FRM-ARM spread declines at first, picks up during 2009, and then declines again. The ARM share mirrors these dynamics, with fixed-rate mortgages being relatively more desirable before the onset of the crisis and the share of adjustable-rate mortgages picking up thereafter. This raises the concern that our results may be affected by common shocks that move mortgage choice and interest rates in a similar fashion across all countries, despite the fact that we control for any potential cross-country contemporaneous correlation in our computation of standard errors.

We therefore additionally control for this possibility by including time fixed effects in our benchmark specifications. The results, reported in the online appendix, confirm the dominant role of the contemporaneous spread. In the full sample of countries, the estimated coefficients $\beta_{C}$ are barely affected by the inclusion of the time fixed effects and remain statistically significant at a $1 \%$ confidence level. The magnitude of the forward-looking component is also robust, especially for the post-2001 period, although this coefficient is less precisely estimated.

\subsection{Cross-sectional patterns}

Having explored the determinants of pure time-series variation in the shares of ARMs, we conclude with a simple cross-country analysis of the determinants of the time-series average ARM shares.

In the top two panels of Figure 2, we plot the country-level average ARM shares and interest rate fixation periods against the average FRM-ARM rate spread over the sample. 
The very strong relationship between interest rate spreads and ARM shares which we documented in the time series dimension seems not to hold when we analyze the cross section of countries. If anything, higher spreads tend to be weakly associated with a lower share of ARMs.

We do not find this surprising, though, given that the institutional structures of the different international mortgage markets are likely to be affected by numerous legal and regulatory factors, foreclosure and bankruptcy rules, different prepayment penalty regimes, as well as supply-side constraints related to the cost structure of banks. We review these factors in detail in the institutional appendix, Badarinza et al. (2014), and highlight the challenges involved in generating comparable mortgage market statistics across countries.

Following Campbell (2013), the bottom part of Figure 2 plots the average ARM share and average interest rate fixation period versus the historical level of inflation volatility in each country. The figure shows that there is a strong positive cross-sectional relationship between the average ARM share and the historical level of inflation volatility, and a negative relationship between the average fixation period and historical inflation volatility. This suggests that there is a significant role for household perceptions of inflation risk in determining household mortgage choice in the long run, consistent with the findings of Malmendier and Nagel (2014). Viewed through this lens, the striking cross-country differences in the structure of mortgage markets seem plausible: in most of Northern and Western Europe and the US, inflation has been contained over the last few decades, and fixed-rate mortgages are more prevalent. In contrast, in Southern Europe and Australia inflation has been more volatile, and higher ARM shares and lower fixation periods are more prevalent.

\section{Conclusion}

Mortgage markets are remarkably heterogeneous across countries, and also vary considerably over time. In a number of countries, including the US, the market share of adjustable-rate mortgages (the ARM share) co-moves with interest rates. In this paper we ask whether households choose the form of their mortgages in response to current interest rates, or also in anticipation of future interest rates. 
We uncover some evidence that households are forward-looking over relatively short periods of time. The spread between the fixed-rate mortgage (FRM) rate and the average rationally expected ARM rate over the next year is often a better predictor of the ARM share than is the spread between the FRM rate and the current ARM rate. The evidence for forward-looking behavior is particularly strong in more recent data since 2001.

Over a longer three-year horizon, however, the current FRM-ARM rate spread tends to have a larger influence on the ARM share than the spread involving rationally expected future rates. Thus households do not seem to anticipate longer-term rate movements in the manner that would be required to minimize the lifetime costs of their mortgages. Instead the current rate spread is an important influence on mortgage choice, as would be implied by a model in which borrowing-constrained households seek low rates in order to maintain the level of current consumption, or to increase the size of the house they can buy when constrained by bank limitations on mortgage interest-to-income ratios.

There is substantial evidence that ARM borrowers in the US do not understand the extent to which ARM rates can vary (Bucks and Pence 2008), and evidence for suboptimal mortgage refinancing in Denmark, the US, and the UK (Andersen et al. 2015, Campbell 2006, Miles 2004). However, we find little evidence in our international dataset supporting a model in which households use an adaptive rule of thumb for forecasting future ARM rates. This does not imply that households are fully informed about the process driving interest rates, or manage their mortgages optimally. We interpret this finding as suggesting that household expectations about future interest rates may require a more complex characterization than simple rules.

We also bring survey data on interest rate forecasts into our analysis and find that the ARM share tends to increase when professional forecasters expect short-term interest rates to decrease during the next year. However the current FRM-ARM spread remains statistically significant even in the presence of this effect, and we continue to reject the hypothesis of rational longer-term rate forecasting even when using survey forecasts as an instrument.

Our analysis of time-series variation in the ARM share concentrates on interest rate movements, but it is equally interesting to ask what drives persistent cross-country variation 
in this share. We have presented evidence that historical volatility in inflation is associated with a high ARM share. This makes sense since inflation volatility makes long-term nominal contracts risky for both borrowers and lenders, or risky for lenders and correspondingly expensive for borrowers in the case where FRMs can be refinanced with minimal prepayment penalties. There are of course many other variables that should help to determine mortgage choice, including, for example, the cost of default and the prevalence of borrowing constraints, and some of these may vary both over time and across countries. These questions remain to be explored in future research. 


\section{References}

Agarwal, S., C. Liu, and N. Souleles, 2007, Reaction of consumer spending and debt to tax rebates: Evidence from consumer credit data, Journal of Political Economy 115, 986-1019

Andersen, S., J.Y. Campbell, K.M. Nielsen, and T. Ramadorai, 2015, Inattention and inertia in household finance: Evidence from the Danish mortgage market, unpublished paper.

Ang, A., G. Bekaert and M. Wei, 2007, Do macro variables, asset markets, or surveys forecast inflation better?, Journal of Monetary Economics, 54, 1163-1212.

Badarinza, C., J.Y. Campbell, G. Kankanhalli, and T. Ramadorai, 2014, Institutional appendix to What calls to ARMs?, http://hhf.oxford-man.ox.ac.uk/node/804.

Badarinza, C., J.Y. Campbell, and T. Ramadorai, 2014, Online appendix to What calls to ARMs?, http://hhf.oxford-man.ox.ac.uk/node/804.

Bardhan, A., R.H. Edelstein, and C.A. Kroll (eds.), 2012, Global Housing Markets: Crises, Policies, and Institutions, John Wiley.

Bernanke, B. S., and M. Gertler, 1995, Inside the black box: The credit channel of monetary policy transmission, Journal of Economic Perspectives 9, 27-48.

Botsch, M. J., and U. Malmendier, 2015, Inflation experiences and contract choice - Evidence from residential mortgages, unpublished paper.

Brueckner, J.K. and J.R. Follain, 1988, The rise and fall of the ARM: An econometric analysis of mortgage choice, Review of Economics and Statistics 70, 93-102.

Bucks, B., and K. Pence, 2008, Do borrowers know their mortgage terms?, Journal of Urban Economics 64, 218-233.

Campbell, J.Y., 2006, Household finance, Journal of Finance 61, 1553-1604.

Campbell, J.Y., 2013, Mortgage market design, Review of Finance 17, 1-33.

Campbell, J.Y. and J.F. Cocco, 2003, Household risk management and optimal mortgage choice, Quarterly Journal of Economics, 118(4), 1449-1494.

Campbell, J.Y. and J.F. Cocco, 2015, A model of mortgage default, Journal of Finance 70, 1495-1554.

Campbell, J.Y. and R.J. Shiller, 1987, Cointegration and tests of present value models, Journal of Political Economy 95, 1062-1088.

Coulibaly, B. and G. Li, 2009, Choice of mortgage contracts: Evidence from the Survey of Consumer Finances, Real Estate Economics 37, 659-673.

Dhillon, U.S., J.D. Shilling, and C.F. Sirmans, 1987, Choosing between fixed and adjustable rate mortgages: Note, Journal of Money, Credit, and Banking, 19, 260-267. 
Di Maggio, M., A. Kermani, and R. Ramcharan, 2015, Monetary policy pass-through: Household consumption and voluntary deleveraging, unpublished paper.

Goggin, J., S. Holton, J. Kelly, R. Lydon, and K. McQuinn, 2012, The financial crisis and the pricing of interest rates in the Irish mortgage market: 2003-2011, Central Bank of Ireland.

Greenspan, A., 2004, Understanding household debt obligations, speech at the Credit Union National Association Governmental Affairs Conference, Washington, DC, available online at http://www.federalreserve.gov/boarddocs/speeches/2004/20040223/.

International Monetary Fund, 2011, Housing finance and financial stability - back to basics?, in: Global Financial Stability Report, April 2011: Durable Financial Stability - Getting There from Here, International Monetary Fund, Washington, DC, pp. 111-142.

Johnson, K., and G. Li, 2011, Are adjustable-rate mortgage borrowers borrowing constrained?, FEDS Working Paper 2011-21, Federal Reserve Board, Washington, DC.

Keys, B., T. Piskorski, A. Seru, and V. Yao, 2014, Mortgage rates, household balance sheets, and the real economy, unpublished paper.

Koijen, R.S.J., O. Van Hemert, and S. Van Nieuwerburgh, 2009, Mortgage timing, Journal of Financial Economics, 93(2), 292-324.

Lea, M., 2011, Alternative forms of mortgage finance: what can we learn from other countries?, in: N. Retsinas and E. Belsky (eds.), Moving Forward: The Future of Consumer Credit and Mortgage Finance, Joint Center for Housing Studies, Harvard University, Cambridge, MA, and Brookings Institution Press, Washington, DC, pp. 118-149.

Lea, M., and A. Sanders, 2011, Government policy and the fixed-rate mortgage, Annual Reviews of Financial Economics 3, 223-234.

Malmendier, U. and Nagel, S., 2014, Learning from inflation experiences, unpublished paper.

Miles, D., 2004, The UK Mortgage Market: Taking A Longer-Term View, HM Treasury, London.

Moench, E., J. Vickery, and D. Aragon, 2010, Why is the market share of adjustable rate mortgages so low? Federal Reserve Bank of New York: Current Issues in Economics and Finance, 16(8), 1-11.

Parker, J., 2014, Why don't households smooth consumption? Evidence from a 25 million dollar experiment, unpublished paper.

Politis, D. N., and Joseph P. Romano, 1994, The stationary bootstrap, Journal of the American Statistical Association, 89, 1303-1313.

Ramadorai, T., 2012, The secondary market for hedge funds and the closed hedge fund premium, Journal of Finance, 67, 479-512.

Souleles, N., 1999, The response of household consumption to income tax refunds, American Economic Review 89, 947-958. 
Taylor, J. B., 1995, The monetary transmission mechanism: An empirical framework, Journal of Economic Perspectives, 9, 11-26.

Villar Burke, J., 2015, Impact of loan contract characteristics on monetary transmission and consumer rent, unpublished paper. 


\section{Table 1}

\section{Summary statistics}

In Panel A, the table reports summary statistics on the share of adjustable-rate mortgages in percent of the total volume of new loans to households, and the average period of initial interest rate fixation (in years). Under the heading S.d., we report time series volatility, measured by the realized standard deviation. The top panel contains the countries which we include in our main panel analysis, for which the time-series standard deviation of the ARM share exceeds five percentage points and the standard deviation of the average initial interest rate fixation period is either unmeasured or equal to at least one year. In Panel B, the table reports selected moments of the time series of 3-month nominal interest rates, as well as corresponding one-year ahead consensus forecasts. Disaggregated forecast data are not available for Denmark, Belgium, Greece and Ireland. In our panel estimation, we use forecasts at the level of the Eurozone for the latter three of these countries.

Panel A

Mortgage market data

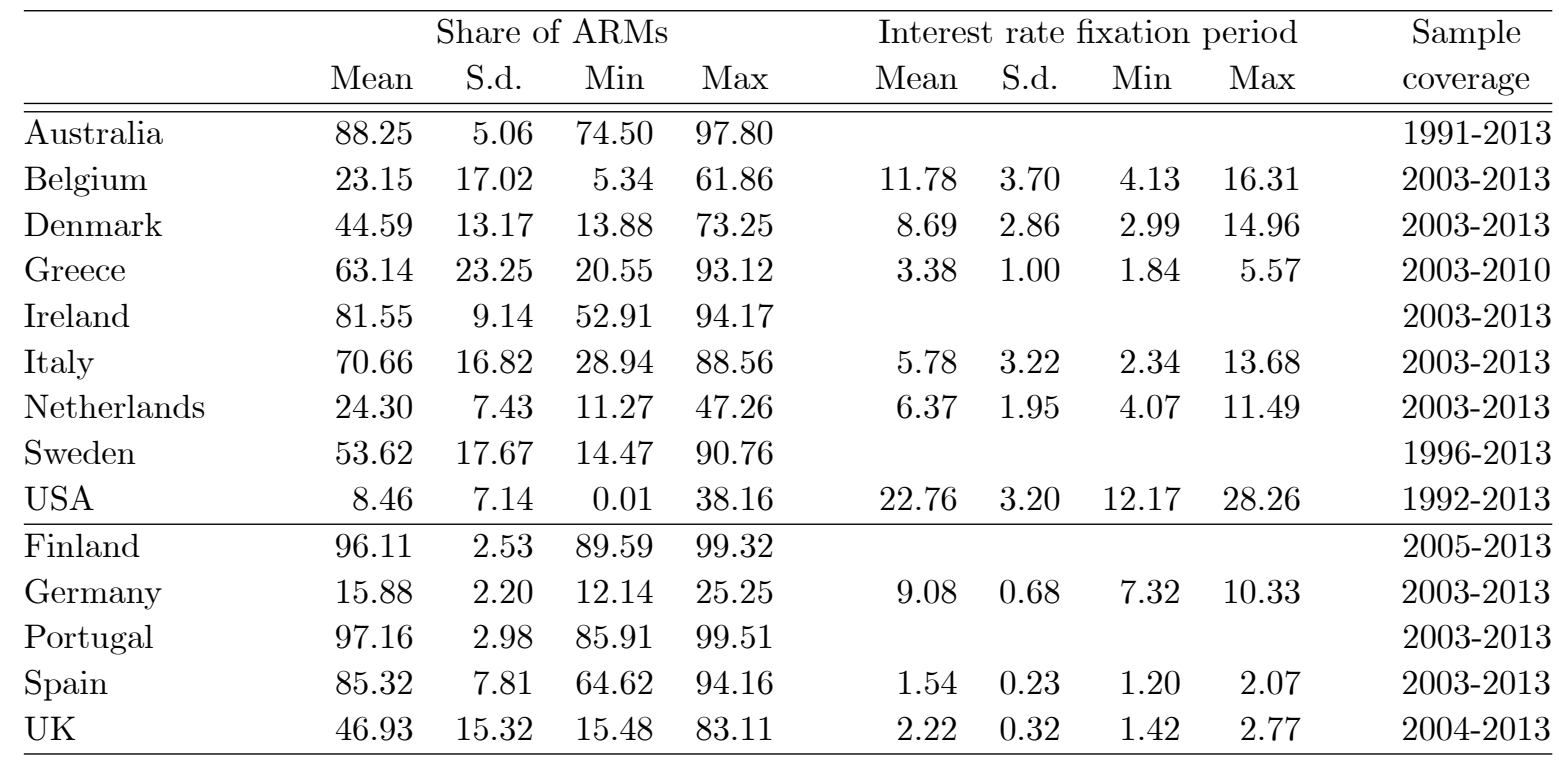

Panel B

Realizations and forecasts of 3-month nominal interest rates

\begin{tabular}{lrrrrrrrrr}
\hline & \multicolumn{3}{c}{ Short-term interest rates } & \multicolumn{3}{c}{ Consensus forecasts } & \multicolumn{2}{c}{ Sample } \\
& Mean & S.d. & Min & Max & Mean & S.d. & Min & Max & coverage \\
\hline \hline Australia & 5.69 & 1.86 & 2.58 & 15.81 & 6.05 & 1.94 & 2.56 & 15.10 & $1990-2013$ \\
Belgium & 2.04 & 1.57 & 0.19 & 5.28 & 2.19 & 1.35 & 0.27 & 4.57 & $2005-2013$ \\
Italy & 5.25 & 4.11 & 0.19 & 18.22 & 5.04 & 3.66 & 0.22 & 13.27 & $1990-2013$ \\
Netherlands & 3.80 & 2.55 & 0.19 & 9.82 & 3.83 & 2.17 & 0.30 & 8.66 & $1990-2013$ \\
Sweden & 5.02 & 3.76 & 0.48 & 20.00 & 5.01 & 3.08 & 0.88 & 14.25 & $1990-2013$ \\
USA & 3.68 & 2.36 & 0.24 & 8.57 & 3.65 & 2.11 & 0.12 & 7.79 & $1990-2013$ \\
\hline
\end{tabular}




\section{Table 2}

\section{Rationality of one-year ahead interest rate forecasts}

The table reports estimation results from regressions of the form:

$$
R_{i, t+12}^{f}-R_{i, t}^{f}=\alpha_{i}+\beta_{i}\left(R_{i, t, t+12}^{f, S}-R_{i, t}^{f}\right)+\varepsilon_{i, t+12} .
$$

In this specification, $R_{i, t}^{f}$ is the 3 -month interest rate in country $i$ in period $t$ and $R_{i, t, t+12}^{f, S}$ is the one-year ahead average consensus forecast in country $i$ in period $t$. Disaggregated forecast data are not available for Denmark, Belgium, Greece and Ireland. In our panel estimation, we use forecasts at the level of the Eurozone for the latter three of these countries. In Panel A, we estimate the coefficients unrestricted country-bycountry. In Panel B, we consider the Eurozone to be a single unit and restrict the slope coefficients $\beta$ to be identical across $i$. Standard errors are reported in parentheses below the coefficients. Statistical significance is indicated through at most three stars, referring to confidence levels of $10 \%, 5 \%$ and $1 \%$ respectively.

\section{Panel A}

Country-by-country estimation

\begin{tabular}{lllcc}
\hline & $\begin{array}{c}\text { Intercept } \\
\alpha_{i}\end{array}$ & $\begin{array}{c}\text { Slope } \\
\beta_{i}\end{array}$ & $\begin{array}{c}\text { p-Value } \\
\beta_{i}=1\end{array}$ & $\begin{array}{c}\text { p-Value } \\
\alpha_{i}=0 \text { and } \beta_{i}=1\end{array}$ \\
\hline \hline Australia & -0.55 & 0.55 & 0.34 & 0.01 \\
Eurozone & $(0.34)$ & $(0.47)$ & & \\
\multirow{2}{*}{ Italy } & $-0.60^{* *}$ & $2.30^{* * *}$ & 0.01 & 0.01 \\
& $(0.27)$ & $(0.51)$ & & \\
Netherlands & -0.25 & $1.36^{* * *}$ & 0.14 & 0.24 \\
\multirow{2}{*}{ Sweden } & $-0.45^{* *}$ & $0.98^{* * *}$ & 0.96 & 0.05 \\
& $(0.19)$ & $(0.31)$ & & \\
USA & $-0.50^{*}$ & $0.82^{* * *}$ & 0.56 & 0.03 \\
& $(0.28)$ & $(0.31)$ & & \\
& -0.28 & $1.16^{* * *}$ & 0.69 & 0.51 \\
\hline
\end{tabular}

Panel B

Panel estimation with fixed effects

\begin{tabular}{ccc}
\hline & $\begin{array}{c}\text { Slope } \\
\beta\end{array}$ & $\begin{array}{c}\mathrm{p} \text {-Value } \\
\beta=1\end{array}$ \\
\hline \hline Panel & $\begin{array}{c}1.02^{* * *} \\
\end{array}$ & 0.92 \\
& $(0.20)$ & \\
\hline
\end{tabular}




\section{Table 3}

Determinants of the ARM share in a cross-country panel: Current mortgage rates vs. rational expectations of future rates

The table reports estimation results from panel instrumental-variables regressions of the form:

$A R M S H A R E_{i, t}=\mu_{i}+\rho A R M S H A R E_{i, t-1}+\beta_{C}\left(F R M_{i, t}-A R M_{i, t}\right)+\beta_{L}\left(F R M_{i, t}-\overline{A R M}_{i, t, t+T}\right)+\nu_{i, t}$,

where $\mu_{i}$ are country-specific fixed effects. $A R M_{i, t}, F R M_{i, t}$ and $\overline{A R M}_{i, t-K, t}$ are used as instruments for $\overline{A R M}_{i, t, t+T}$. In our benchmark case, $T=3$ years. The first-stage model specification is given by:

$$
\overline{A R M}_{i, t, t+T}=\alpha_{i}+\gamma_{1} A R M_{i, t}+\gamma_{2} F R M_{i, t}+\gamma_{3} \overline{A R M}_{i, t-K, t}+\gamma_{4} B_{i, t}^{5}+\gamma_{5} R_{i, t}^{f}+\varepsilon_{i, t} .
$$

We show the results for $K=1$ year. All estimations cover the same sample as the one with $T=3$ years. We report bootstrap standard errors in parentheses. Statistical significance is indicated through at most three stars, referring to confidence levels of $10 \%, 5 \%$ and $1 \%$ respectively.

\begin{tabular}{lcccc}
\hline & Benchmark $(T=3$ years $)$ & \multicolumn{2}{c}{$T=1$ year } \\
\hline & Panel & $\begin{array}{c}\text { Panel } \\
\text { excl. USA }\end{array}$ & Panel & $\begin{array}{c}\text { Panel } \\
\text { excl. USA }\end{array}$ \\
\hline \hline Full sample & & & \\
\hline$\beta_{C}$ & $0.74^{* * *}$ & $0.87^{* * *}$ & -0.08 & -0.11 \\
& $(0.25)$ & $(0.30)$ & $(0.42)$ & $(0.41)$ \\
$\beta_{L}$ & 0.31 & $0.46^{*}$ & $1.23^{* * *}$ & $1.53^{* * *}$ \\
& $(0.26)$ & $(0.26)$ & $(0.41)$ & $(0.42)$ \\
\hline Post-2001 & & & & \\
\hline$\beta_{C}$ & $0.83^{* * *}$ & $1.05^{* * *}$ & -0.37 & -0.22 \\
& $(0.31)$ & $(0.37)$ & $(0.46)$ & $(0.53)$ \\
$\beta_{L}$ & $0.71^{* * *}$ & $0.74^{* *}$ & $1.74^{* * *}$ & $1.85^{* * *}$ \\
& $(0.24)$ & $(0.30)$ & $(0.46)$ & $(0.50)$ \\
\hline
\end{tabular}




\section{Table 4}

Determinants of the ARM share at the country level:

Current mortgage rates vs. rational expectations of future rates

The table reports estimation results from country-by-country and panel instrumental-variables regressions where $A R M_{i, t}, F R M_{i, t}$ and $\overline{A R M}_{i, t-K, t}$ are used as instruments for $\overline{A R M}_{i, t, t+T}$, with $T=3$ years and $K=1$ year:

$$
\overline{A R M}_{i, t, t+T}=\alpha_{i}+\gamma_{i, 1} A R M_{i, t}+\gamma_{i, 2} F R M_{i, t}+\gamma_{i, 3} \overline{A R M}_{i, t-K, t}+\gamma_{i, 4} B_{i, t}^{5}+\gamma_{i, 5} R_{i, t}^{f}+\varepsilon_{i, t} .
$$

The second-stage model specification is given by:

$$
\begin{aligned}
\operatorname{ARMSHARE}_{i, t}= & \mu_{i}+\rho_{i} A R M S H A R E_{i, t-1}+\beta_{i, C}\left(F R M_{i, t}-A R M_{i, t}\right) \\
& +\beta_{i, L}\left(F R M_{i, t}-\overline{A R M}_{i, t, t+T}\right)+\nu_{i, t} .
\end{aligned}
$$

Correlation coefficients among regressors are reported under the column heading $\Gamma$. Statistical significance is reported through at most three stars, referring to confidence levels of $10 \%, 5 \%$ and $1 \%$ respectively, based on bootstrap standard errors.

\begin{tabular}{lccccccr}
\hline \multicolumn{7}{c}{ First-stage estimation } \\
\hline & $\gamma_{1}$ & $\gamma_{2}$ & $\gamma_{3}$ & $\Gamma_{\gamma_{1}, \gamma_{2}}$ & $\Gamma_{\gamma_{1}, \gamma_{3}}$ & $\bar{R}^{2}$ & obs. \\
\hline \hline Full sample & & & & & & & \\
\hline Australia & $0.89^{* * *}$ & 0.12 & $-0.19^{* *}$ & 0.91 & 0.84 & 0.66 & 222 \\
Belgium & $-0.77^{* * *}$ & -0.37 & -0.17 & 0.87 & 0.75 & 0.83 & 72 \\
Denmark & -0.27 & -0.44 & $-0.97^{* * *}$ & 0.95 & 0.77 & 0.61 & 83 \\
Greece & -0.05 & 0.03 & $-1.01^{* * *}$ & -0.14 & 0.48 & 0.96 & 47 \\
Ireland & -0.55 & $-0.58^{* *}$ & $-0.42^{* * *}$ & 0.94 & 0.75 & 0.77 & 84 \\
Italy & 1.06 & $-1.04^{* * *}$ & $-0.56^{* *}$ & 0.83 & 0.80 & 0.61 & 84 \\
Netherlands & $0.81^{* * *}$ & $-1.57^{* * *}$ & 0.05 & 0.71 & 0.79 & 0.76 & 84 \\
Sweden & -0.01 & $1.28^{* * *}$ & $-0.33^{* * *}$ & 0.94 & 0.83 & 0.67 & 166 \\
USA & $0.33^{* *}$ & $-0.47^{*}$ & 0.29 & 0.74 & 0.84 & 0.70 & 216 \\
\hline Panel & $0.34^{* * *}$ & $0.25^{* * *}$ & $-0.28^{* * *}$ & 0.91 & 0.93 & 0.85 & 1058 \\
\hline Panel (excl. USA) & $0.62^{* * *}$ & $0.19^{* *}$ & $-0.34^{* * *}$ & 0.95 & 0.94 & 0.87 & 842 \\
\hline Post-2001 & & & & & & & \\
\hline Australia & -0.06 & -0.07 & $-0.18^{*}$ & 0.82 & 0.58 & 0.17 & 120 \\
Sweden & $0.75^{*}$ & 0.07 & $-0.36^{* * *}$ & 0.96 & 0.80 & 0.36 & 120 \\
USA & $0.64^{* *}$ & -0.81 & 0.39 & 0.82 & 0.82 & 0.62 & 120 \\
\hline Panel & $0.40^{*}$ & -0.15 & $-0.42^{* * *}$ & 0.91 & 0.90 & 0.84 & 814 \\
\hline Panel (excl. USA) & $0.31^{* *}$ & -0.12 & $-0.43^{* * *}$ & 0.93 & 0.90 & 0.87 & 694 \\
\hline & & & & & & & \\
\hline
\end{tabular}




\section{Table 4}

Determinants of the ARM share at the country level:

Current mortgage rates vs. rational expectations of future rates (continued)

\begin{tabular}{|c|c|c|c|c|c|c|}
\hline \multicolumn{7}{|c|}{ Second-stage estimation } \\
\hline & $\rho$ & $\beta_{C}$ & $\beta_{L}$ & $\Gamma_{\beta_{C}, \widehat{\beta_{L}}}$ & $\bar{R}^{2}$ & obs. \\
\hline \multicolumn{7}{|l|}{ Full sample } \\
\hline Australia & $0.90^{* * *}$ & 0.41 & -0.05 & 0.22 & 0.84 & 222 \\
\hline Belgium & $0.84^{* * *}$ & $3.47^{* * *}$ & $2.43^{* * *}$ & -0.11 & 0.97 & 72 \\
\hline Denmark & $0.81^{* * *}$ & -0.41 & -0.06 & -0.47 & 0.63 & 83 \\
\hline Greece & $0.97 * * *$ & 1.04 & 2.66 & 0.69 & 0.98 & 47 \\
\hline Ireland & $0.88^{* * *}$ & 0.75 & 0.39 & 0.11 & 0.74 & 84 \\
\hline Italy & $0.96^{* * *}$ & $2.02^{*}$ & 0.05 & 0.09 & 0.99 & 84 \\
\hline Netherlands & $0.92^{* * *}$ & $1.32^{* *}$ & 0.49 & 0.22 & 0.93 & 84 \\
\hline Sweden & $0.96^{* * *}$ & 0.64 & 0.53 & -0.56 & 0.93 & 166 \\
\hline USA & $0.92^{* * *}$ & $1.42^{* *}$ & $-1.13^{* *}$ & 0.63 & 0.93 & 216 \\
\hline Panel & $0.95^{* * *}$ & $0.74^{* * *}$ & 0.31 & 0.43 & 0.99 & 1058 \\
\hline Panel (excl. USA) & $0.95^{* * *}$ & $0.87^{* * *}$ & $0.46^{*}$ & 0.29 & 0.98 & 842 \\
\hline \multicolumn{7}{|l|}{ Post-2001 } \\
\hline Australia & $0.99^{* * *}$ & -0.04 & 0.70 & 0.22 & 0.92 & 120 \\
\hline Sweden & $0.95^{* * *}$ & -0.11 & 0.12 & -0.67 & 0.89 & 120 \\
\hline USA & $0.95^{* * *}$ & 0.19 & -0.58 & 0.36 & 0.94 & 120 \\
\hline Panel & $0.95^{* * *}$ & $0.83^{* * *}$ & $0.71^{* * *}$ & 0.28 & 0.99 & 814 \\
\hline Panel (excl. USA) & $0.95^{* * *}$ & $1.05^{* * *}$ & $0.74^{* *}$ & 0.27 & 0.98 & 694 \\
\hline
\end{tabular}




\section{Table 5}

Determinants of the ARM share at the country level:

Current mortgage rates vs. adaptive expectations of future rates

The table reports estimation results from the panel specification:

$$
\begin{aligned}
\operatorname{ARMSHARE} E_{i, t}= & \mu_{i}+\rho_{i} A R M S H A R E_{i, t-1}+\beta_{i, C}\left(F R M_{i, t}-A R M_{i, t}\right) \\
& +\beta_{i, L}\left(F R M_{i, t}-\overline{A R M}_{i, t-K, t}\right)+\nu_{i, t},
\end{aligned}
$$

which we estimate for each country separately, as well as in a pooled panel setup with country-specific fixed effects. In the two rightmost columns we report estimation results when excluding the lagged dependent variable, i.e. imposing the restriction $\rho_{i}=0$. Statistical significance is reported through at most three stars,

\begin{tabular}{|c|c|c|c|c|}
\hline & \multicolumn{2}{|c|}{ Benchmark $(K=1$ year $)$} & \multicolumn{2}{|c|}{ Excluding lagged term } \\
\hline & $\beta_{C}$ & $\beta_{L}$ & $\beta_{C}$ & $\beta_{L}$ \\
\hline \multicolumn{5}{|l|}{ Full sample } \\
\hline Australia & 0.33 & 0.05 & $3.56^{* * *}$ & $-1.09^{* * *}$ \\
\hline Belgium & $1.94^{* *}$ & $-3.46^{* * *}$ & $21.15^{* * *}$ & 0.67 \\
\hline Denmark & 0.50 & -1.62 & $5.51^{* * *}$ & $-6.58^{* * *}$ \\
\hline Greece & $6.61^{*}$ & -4.83 & $34.35^{* * *}$ & 8.52 \\
\hline Ireland & 0.81 & $-2.62^{* * *}$ & -0.01 & $-12.94^{* * *}$ \\
\hline Italy & $2.59^{* * *}$ & $-2.83^{* * *}$ & $8.58^{* * *}$ & $15.87^{* * *}$ \\
\hline Netherlands & $1.80^{* * *}$ & -0.44 & $7.10^{* * *}$ & $6.08^{* * *}$ \\
\hline Sweden & 0.56 & $-0.95^{* *}$ & $10.94^{* *}$ & -1.24 \\
\hline USA & 0.04 & $1.08^{* *}$ & $-1.75^{* *}$ & $8.99^{* * *}$ \\
\hline Panel & $1.17^{* * *}$ & $-0.53^{* * *}$ & $10.23^{* * *}$ & $-1.01^{*}$ \\
\hline Panel excl. USA & $1.27^{* * *}$ & $-0.61^{* * *}$ & $11.68^{* * *}$ & $-1.72^{* * *}$ \\
\hline \multicolumn{5}{|l|}{ Post-2001 } \\
\hline Australia & 0.22 & 0.13 & $6.82^{* * *}$ & $-2.52^{* * *}$ \\
\hline Sweden & 0.13 & $-1.37^{* * *}$ & $17.04^{* * *}$ & $-3.76^{* *}$ \\
\hline USA & -0.24 & 0.26 & $-3.40 * * *$ & 4.12 \\
\hline Panel & $1.23^{* * *}$ & $-0.73^{* * *}$ & $12.58^{* * *}$ & $-1.95^{* * *}$ \\
\hline Panel excl. USA & $1.48^{* * *}$ & $-0.80^{* * *}$ & $14.45^{* * *}$ & $-2.37^{* * *}$ \\
\hline
\end{tabular}
referring to confidence levels of $10 \%, 5 \%$ and $1 \%$ respectively, based on bootstrap standard errors. 


\section{Table 6}

Determinants of the ARM share in a cross-country panel:

Current mortgage rates vs. survey-based expectations of future rates

The table reports estimation results from panel regressions of the form:

$$
\begin{aligned}
A R M S H A R E_{i, t} & =\mu_{i}+\rho A R M S H A R E_{i, t-1}+\beta_{C}\left(F R M_{i, t}-A R M_{i, t}\right)+\beta_{L}\left(F R M_{i, t}-\overline{A R M}_{i, t, t+T}\right) \\
& +\beta_{S}\left(R_{i, t}^{f}-R_{i, t, t+12}^{f, S}\right)+\nu_{i, t},
\end{aligned}
$$

where $\mu_{i}$ are country-specific fixed effects and $R_{i, t, t+12}^{f, S}$ is the consensus forecast of the one-year ahead nominal interest rate. The first-stage model specification is given by:

$$
\overline{A R M}_{i, t, t+T}=\alpha_{i}+\gamma_{1} A R M_{i, t}+\gamma_{2} F R M_{i, t}+\gamma_{3} \overline{A R M}_{i, t-K, t}+\gamma_{4} B_{i, t}^{5}+\gamma_{5} R_{i, t}^{f}+\gamma_{6} R_{i, t, t+12}^{f, S}+\varepsilon_{i, t} .
$$

We show the results for the case $K=1$ year. We report bootstrap standard errors in parentheses. Statistical

\begin{tabular}{|c|c|c|c|c|}
\hline & \multicolumn{2}{|c|}{ Benchmark ( $T=3$ years) } & \multicolumn{2}{|c|}{$T=1$ year } \\
\hline & Panel & $\begin{array}{c}\text { Panel } \\
\text { excl. USA }\end{array}$ & Panel & $\begin{array}{c}\text { Panel } \\
\text { excl. USA }\end{array}$ \\
\hline \multicolumn{5}{|c|}{ Full sample } \\
\hline \multirow[t]{2}{*}{$\beta_{C}$} & $0.92^{* * *}$ & $1.59^{* * *}$ & -0.08 & 0.66 \\
\hline & $(0.28)$ & $(0.33)$ & $(0.45)$ & $(0.48)$ \\
\hline \multirow[t]{2}{*}{$\beta_{L}$} & 0.18 & 0.22 & $1.26^{* * *}$ & $1.07^{* * *}$ \\
\hline & $(0.25)$ & $(0.23)$ & $(0.43)$ & $(0.41)$ \\
\hline \multirow[t]{2}{*}{$\beta_{S}$} & $0.48^{*}$ & $1.32^{* * *}$ & 0.13 & $0.86^{* *}$ \\
\hline & $(0.25)$ & $(0.36)$ & $(0.21)$ & $(0.34)$ \\
\hline \multicolumn{5}{|c|}{ Post-2001 } \\
\hline \multirow[t]{2}{*}{$\beta_{C}$} & $1.08^{* *}$ & $2.11^{* * *}$ & -0.18 & 1.23 \\
\hline & $(0.48)$ & $(0.48)$ & $(0.59)$ & $(0.96)$ \\
\hline \multirow[t]{2}{*}{$\beta_{L}$} & 0.47 & 0.15 & $1.51^{* * *}$ & 0.85 \\
\hline & $(0.29)$ & $(0.37)$ & $(0.49)$ & $(0.78)$ \\
\hline \multirow[t]{2}{*}{$\beta_{S}$} & 0.49 & $1.76^{* * *}$ & 0.06 & 1.21 \\
\hline & $(0.38)$ & $(0.59)$ & $(0.42)$ & $(0.76)$ \\
\hline
\end{tabular}
significance is indicated through at most three stars, referring to confidence levels of $10 \%, 5 \%$ and $1 \%$ respectively. 


\section{Table 7}

Determinants of the average fixation period in a cross-country panel:

Current mortgage rates vs. rational expectations of future rates

The table reports estimation results from panel instrumental-variables regressions of the form:

$$
A V G F I X_{i, t}=\mu_{i}+\rho A V G F I X_{i, t-1}-\beta_{C}\left(F R M_{i, t}^{\eta}-A R M_{i, t}\right)-\beta_{L}\left(F R M_{i, t}^{\eta}-\overline{A R M}_{i, t, t+T}\right)+\nu_{i, t},
$$

with country-specific fixed effects. $A V G F I X_{i, t}$ is the average fixation period and $F R M_{i, t}^{\eta}$ is the rate on mortgage loans corresponding to a fixation period $\eta$. For all countries, we choose $\eta=$ 'above 10 years'. $A R M_{i, t}, F R M_{i, t}^{\eta}$ and $\overline{A R M}_{i, t-K, t}$ are used as instruments for $\overline{A R M}_{i, t, t+T}$. In our benchmark case, $T=3$ years. The first-stage model specification is given by:

$$
\overline{A R M}_{i, t, t+T}=\alpha_{i}+\gamma_{1} A R M_{i, t}+\gamma_{2} F R M_{i, t}^{\eta}+\gamma_{3} \overline{A R M}_{i, t-K, t}+\gamma_{4} B_{i, t}^{5}+\gamma_{5} R_{i, t}^{f}+\varepsilon_{i, t} .
$$

We show the results for $K=1$ year. All estimations cover the same sample as the one with $T=3$ years. Statistical significance is reported through at most three stars, referring to confidence levels of $10 \%, 5 \%$ and $1 \%$ respectively, based on bootstrap standard errors.

\begin{tabular}{lcccc}
\hline & Benchmark $(T=3$ years $)$ & \multicolumn{2}{c}{$T=1$ year } \\
\hline & Panel & $\begin{array}{c}\text { Panel } \\
\text { excl. USA }\end{array}$ & Panel & $\begin{array}{c}\text { Panel } \\
\text { excl. USA }\end{array}$ \\
\hline \hline Full sample & & & \\
\hline$\beta_{C}$ & $0.18^{* * *}$ & $0.22^{* * *}$ & -0.10 & -0.18 \\
& $(0.06)$ & $(0.07)$ & $(0.10)$ & $(0.12)$ \\
$\beta_{L}$ & $0.16^{* * *}$ & $0.23^{* * *}$ & $0.38^{* * *}$ & $0.50^{* * *}$ \\
& $(0.05)$ & $(0.05)$ & $(0.09)$ & $(0.09)$ \\
\hline Post-2001 & & & & \\
\hline$\beta_{C}$ & $0.13^{* *}$ & $0.22^{* * *}$ & $-0.23^{* *}$ & -0.18 \\
& $(0.06)$ & $(0.07)$ & $(0.10)$ & $(0.12)$ \\
$\beta_{L}$ & $0.22^{* * *}$ & $0.23^{* * *}$ & $0.46^{* * *}$ & $0.50^{* * *}$ \\
& $(0.05)$ & $(0.05)$ & $(0.09)$ & $(0.09)$ \\
\hline
\end{tabular}


Figure 1

Time series of ARM share and FRM-ARM spread at the country level

The figure illustrates the dynamics of the share of adjustable-rate mortgages in percent of the total volume of new loans to households (on the left axis) and the contemporaneous spread between the FRM and ARM rates (on the right axis). For the US, imputed values are used for the ARM rate during the periods November 2008 to March 2009, August 2011 to November 2011 and October 2012 to April 2013. Details of the imputation method are given in the online appendix . Mortgage interest rates correspond to volume-weighted averages of new loans advanced during the respective month, in domestic currency and to domestic households.
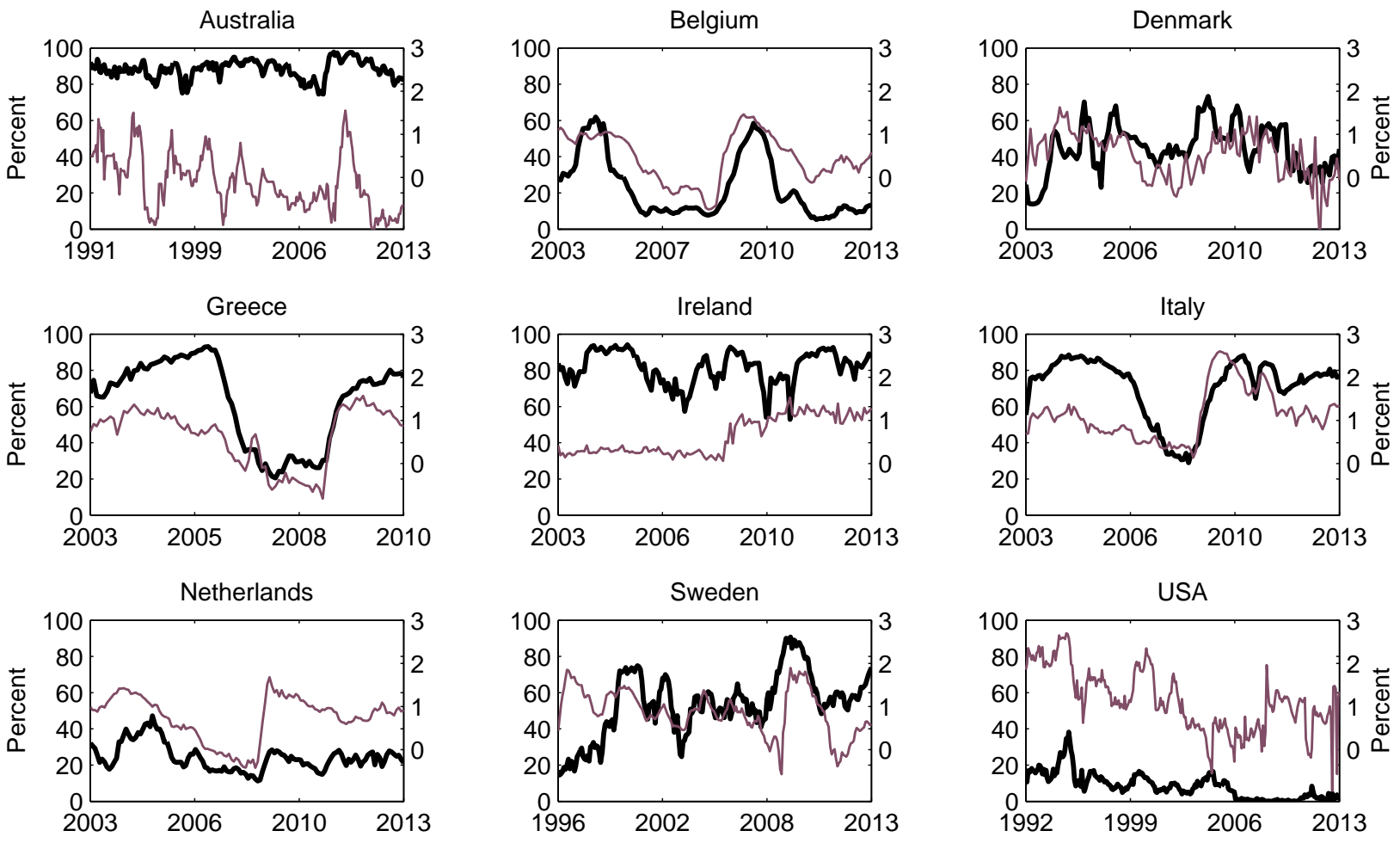

- ARM share (left axis)

FRM-ARM spread (right axis) 


\section{Figure 2}

Cross-country patterns in mortgage market structure and historical inflation volatility

Inflation volatility is measured as the realized standard deviation of the monthly year-on-year inflation rate during the entire available sample period. For Australia, Belgium, Germany, Spain and the US, the series starts in 1956, Italy in 1958, Greece in 1960, Finland, the Netherlands, Portugal and Sweden in 1961, Ireland in 1970, Denmark in 1981 and the UK in 1989. Average fixation periods are derived based on the market share of mortgages falling within different fixation period categories. The green dots are distinguishing countries which are not included in the panel analysis. The FRM-ARM spread refers to the difference between the volume-weighted averages of interest rates on fixed-rate (FRM) versus adjustable-rate (ARM) mortgage loans advanced during the respective month.
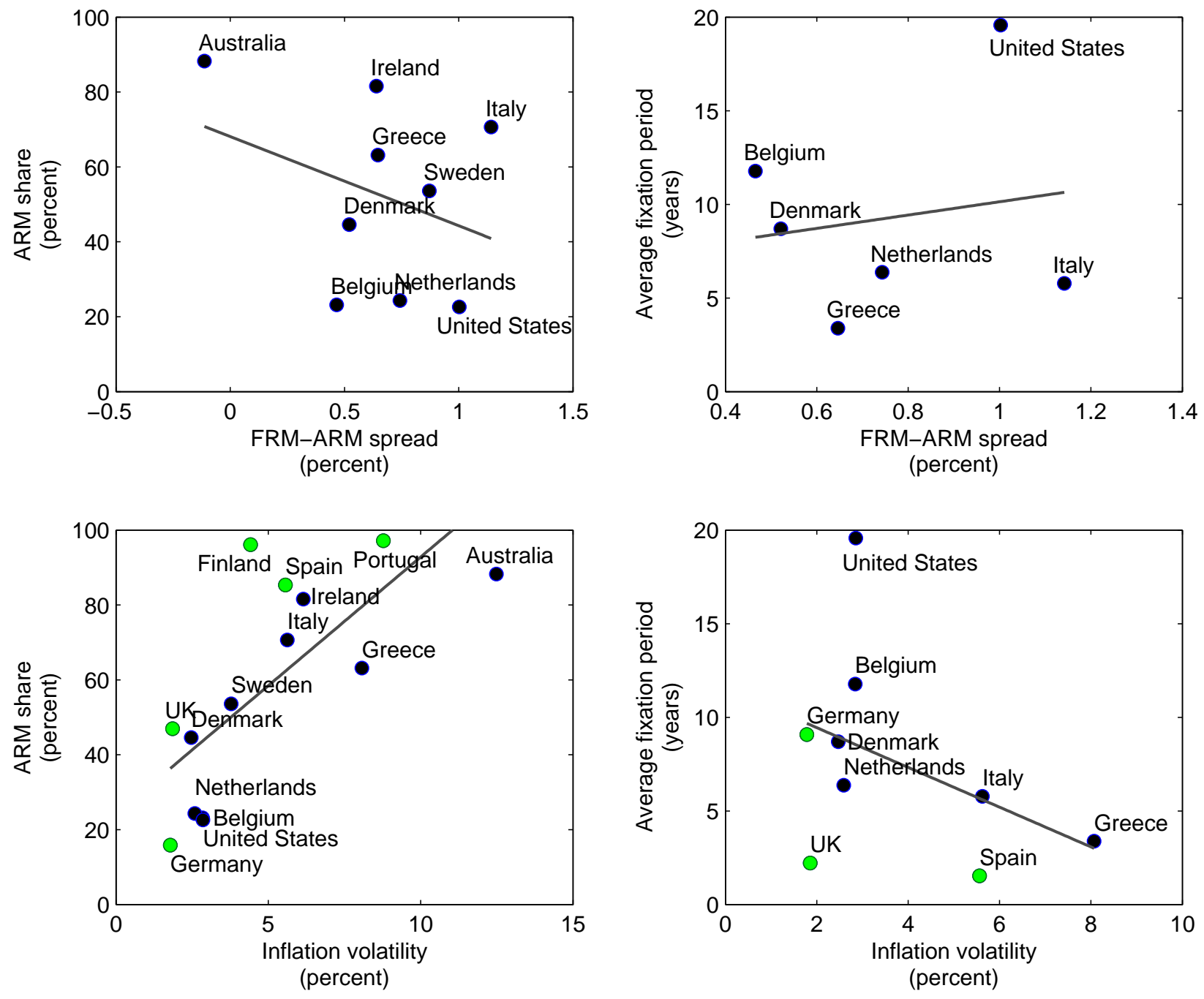